\title{
Pengembangan Produksi Merchandise Dengan Sablon Manual Desa Wisata Adat Kampung Urug Kabupaten Bogor - Jawa Barat
}

\author{
Emmidia Djonaedi ${ }^{1}$, HB Rudi Kusumantoro ${ }^{2}$, Endang Yuniarti ${ }^{3}$, \\ Dini Handayani ${ }^{4}$, Muhammad Budi Gunawan ${ }^{5}$ \\ 1,2,3,4,5Jurusan Teknik Grafika dan Penerbitan, Program Studi Teknik Grafika, Politeknik Negeri Jakarta \\ email: ${ }^{1}$ emmidia.djonaedi@grafika.pnj.ac.id, ${ }^{2}$ hb rudi k@yahoo.com, ${ }^{3}$ endang.yuniarti@grafika.pnj.ac.id, \\ dini.handayani83@gmail.com, ${ }^{5}$ muhammadbudigunawan@gmail.com
}

\begin{abstract}
Abstrak
Marketing pariwisata untuk Desa wisata Kampung Urug, Bogor penting untuk dilakukan guna memberdayakan maasyarakat dan mempromosikan keindahan alam serta budaya yang ada. Desa ini merupakan salah desa yang menjadi perhatian oleh Pemerintah Kabupaten Bogor, Jawa Barat. Salah satu upaya mempromosikan Desa wisata Kampung Urug adalah menggunakan souvenir yang bergambar khas kampong Urug dan diproduksi oleh masyarakat Kampung. Saat ini kampong Urug belum mempunyai buah tangan khusus yang dibisa dijadikan cinderamata atau Merchandise. Penduduk Kampong Urug rata-rata bekerja sebagai petani, peternak, sedangkan dan ibu rumah tangga. Program studi Teknik Grafika mempunyai peluang untuk membuat produk merchandise khusus dari Desa Wisata Kampung Urug, Bogor. Dengan adanya pembuatan merchandise yaitu berupa sablon manual pada media tekstile (pouch) serta mesin cetak digital yang user friendly untuk keberlangsungan cetak buku panduan wisata kampong adat, kemudian hasilnya menjadi buah tangan untuk pengunjung Desa Wisata Kampung Urug. Kegiatan pelatihan ini akan menambah pengetahuan kepada penduduk Kampung Urug hasil dari pelatihan menjadi pemasukan bagi masyarakat Kampung Urug.
\end{abstract}

Kata kunci- kampung urug, mechandise, sablon manual, desa wisata

\section{PENDAHULUAN}

Indonesia mempunyai ragam budaya dan keindahan alam dan keindahan alam yang luar biasa. Ragam budaya ini perlu di sebar luaskan untuk mengundang wisatawan datang. Model yang berbasiskan ke arifan local dilakukan untuk memberikan alternative pemilihan destinasi wisata yang akan dikunjungi oleh wisatawan. Kegiatan wiata juga melibatkan komunitas adat yang menjadi gatekeeper saat perencanaan, pelaksanaan dan evaluasi kegiatan disetiap daerah. Beberapa kegiatan yang harus diperhatikan antara lain : hak budaya local, partisipasi masyarakat, konservasi sumber daya, pendidikan, pelatihan, promosi, akuntabilitas serta pemantauan dan evaluasi. Termasuk salah satunya adalah Desa Wisata Kampung Urug, Bogor, Jawa Barat. (Nugraha, 2017).

Kampung Urug berasal dari kata "Guru" yang berdasarkan etimologi rakyat artinya dipatuhi dan diteladani. Kampung ini terletak di Jawa B yang jaraknya kurang lebih $48 \mathrm{Km}$ dari Ibukota Kabupaten Bogor. Salah satu daya tarik wisata di kampung Desa wisata adat kampong Urug adalah kealamian alam tempat mereka tinggal. Kekayaan budaya dan alam di suatu daerah menjadi daya tarik tersendiri bagi para wisatawan untuk mengunjunginya. Menurut situs Kabupaten Bogor, Desa wisata adat kampong Urug merupakan desa sisa peradaban masa silam yang sampai saat ini nilai - nilai ketradisiannya masih dipertahankan. (Anon., 2018)

Menurut data dari kepala desa, Kampung Adat Urug mempunyai tingkat kunjungan wisata rata - rata $80-100$ orang setiap bulan dan jika pada hari - hari besar bisa mencapai $100-200$ orang per hari. Namun, sebagai desa wisata, Kampung Urug belum mempunyai media promosi seperti buah tangan khusus yang dibisa dijadikan cinderamata dari Kampung Urug seperti kaos, goodie bag, pouch, sapu tangan/taplak meja dan bentuk lainnya pada media textile. Menurut masyarakat, selama ini promosi pariwisata di kampong mereka sangatlah kurang. Sementara banyak destinasi wisata adat yang perlu diketahui masyarakat kita khususnya remaja dan anak-anak. Hal ini untuk meningkatkan pengetahuan masyarakat akan budaya dan adat isti adat local.

Untuk mewujudkan hal tersebut harus ada kesamaan dan partisipasi masyarakat agar bisa bersama-sama memajukan pariwisata adat kampong Urug. Partisipasi ini tidak hanya dari pemerintah setempat, namun juga dari instansiinstansi lainnya seperti instansi pendidikan yang 
melakukan kegiatan pengabdian kepada masyarakat seperti program ini.

\section{METODOLOGI PELAKSANAAN}

Untuk mengatasi permasalahan promosi keberadaan desa wisata adat Kampung Urug diperlukan beberapa strategi. Berdasarkan penelitian sebelumnya bahwa prinsip pengembangan e ekowisata memerlukan: 1) pemberdayaan dan pengoptimalkan partispasi masyarakat setempat secara berkala;2) memberikan pemahaman yang dapat memberikan peluang kepada wisatawan untuk menikmati alam setempat; 3) pengaturan jumlah pengunjung terkait daya tamping dan daya dukung kawasan secara informative dan terakhir 4) dengan pemasaran yang jujur dan pertanggung jawab karena perlu menjaga konservasi alam dan nilai-nilai social budaya serta tradisi keagamaan setempat serta mentaaati peraturan perundangan yang berlaku (Putra, 2010).

Salah satu hal yang mendukung kegiatan ini adalah membuat media promosi atau souvenir untuk menunjukkan identitas kampong sekaligus melakukan kegiatan pelatihan Sablon manual. Kegiatan ini akan membantu masyarakat merancang dan membuat cinderamata yang berasal dari kain dan dihias dengan gambar melalu proses cetak sablon manual atau disebut screen printing. Sablon manual atau screen printing merupakan teknik printing stensil yang banyak digunakan karena harganya murah terutama untuk dekorasi pada tekstile, keramik, gelas dan elektronik. Teknik ini bisa digunakan pada media yang datar atau silinder. Tenik stensil yng igunakan dengan menuangkan dan menekan tinta pasta ke atas screen yang telah di beri gambar dan dilanjutkan dengan pengeringan. (Sauer, 2004)

Proses pembuatan souvenir ini dibuat dengan cara yang mudah dan barang habis pakai mudah didapat sehingga memudahkan masyarakat untuk mempelajari dan mengaplikasikannya bila akan diproduksi ulang. Selama ini Desa wisata Kampung Urug belum mempunyai souvenir khusus yang dibisa dijadikan cinderamata seperti kaos, goodie bag, pouch, sapu tangan/taplak meja dan bentuk lainnya pada media textile.

Proses pembuatan souvenir ini melibatkan dosen, teknisi dan mahasiswa untuk membantu proses pembuatan souvenir dengan metode sablon manual pada media tekstile. Proses sablon menggunakan tinta sablon dua warna yaitu kuning dan coklat. Acuan cetak pada screen sablon dibuat dua pola yaitu untuk pola warna kuning dan pola warna kuning. Pada setiap souvenir masing masing warna diaplikasikan satu persatu dengan hati-hati untuk mendapatkan posisi gambar yang presisi.

\section{HASIL DAN PEMBAHASAN}

Pelaksanaan pengabdian masyarakat dilakukan 21-22 September 2018 di Kampung Urug. Sebelumnya Pembelian alat dan bahan dilakukan oleh dosen bersama dengan teknisi dan mahasiswa,. Proses pembuatan merchandise yang bisa langsung digunakan atau dijual oleh masyarakat kampong Urug juga dikerjakan oleh teknisi dan mahasiswa yang sudah terbiasa mengerjakan kegiatan sablon dan menghasilkan produk yang cukup baik kualitasnya. Design gambar dilakukan oleh mahasiswa design grafis dan menyesuaikan dengan karakteristik kampong urug. Selanjutnya pada saat kunjungan ke Kampung Urug, dosen dan teknisi dan mahasiswa memberikan Pelatihan pembuatan souvenir tersebut kepada masyarakaat kampong urug yang telah di koordinir dan dipilih oleh kepala desa setempat. Kepala desa mengundang masyarakat sekitar untuk berpartisapasi pada kegiatan ini. Kurang lebih 75 warga mengikuti pelatihan ini.

Kegiatan diawali dengan persiapan bahan habis pakai dan peralatan penunjang yang digunakan untuk memproduksi merchandise sablon. Persiapan bahan dan alat perlengkapan sablon antara lain adalah tas kanvas tenteng dan serut sebagai goodie bag, pouch dan kain slayer untuk bahan yang akan di sablon. Bahan untuk menyablon antara lain adalah : obat emulsi afdruk, gliserin, tinta rubber putih dan warna, pigmen, extender, pengencer tinta padat M3 dan remover stencil afdruk (bremol). Alat yang diperlukan untuk proses sablon adalah screen dengan berbagai macam ukuran (T55), rakel kotak, alas media cetak, catokn screen, lampu neon panjang, busa, pengering rambut, kabel terminal, isolasi, meja sablon. Semua bahan dan alat tersebut digunakan untuk membuat merchandise dan untuk melatih masyarakat kampong urug.

Berikut ini langkah-langkah Proses Cetak Saring atau sablon pada media textile:

1. Degreasing yaitu membersihkan screen yang akan digunakan, agar tidak ada kotoran yang menyumbat lubang mesh sehingga membuat hasil lapisan afdruk tidak merata. Screen yang digunakan biasanya terbuat dari sutra, nylon, polyester ata stainless steel, dengan ukuran mesh dari 10 - 450 mesh per inch. (Sauer, 
2004). Pada proses ini menggunakan screen nylon dan menggunakan mesh 55 (T55).

2. Coating Emulsion yaitu melapisi permukaan screen bagian luar dan dalam dengan cairan afdruk yang telah di racik dengan komposisi 8 (emulsi) : 1 (Photo sensitive), dengan alat bantu coater dan proses pelapisan dilakukan 1 arah. Proses pelapisan dengan airan afdruk ini berfungsi untuk menutup lubang pada screen agar saat proses cetak tinta tidak keluar pada area yang tidak bergambar.

3. Drying adalah proses pengeringan permukaan screen yang telah dilapisi cairan afdruk dengan bantuan pengering rambut. Pemeriksaaan tingkat kekeringan lapisan dapat dilakukan dengan cara meraba dan memukul mukul ringan, jika lapisan masih terasa lengket dan tidak berbunyi ketika di pukul ringan, berarti lapisan belum terlalu kering, namun jika ketika diraba terasa tidak lengket dan dipukul ringan mengeluarkan suara layaknya gendang, dapat diartian bahwa lapisan sudah kering.

4. Proses Persiapan gambar dilakukan dengan mencetak gambar dengan printer atau mesin cetak. Pada umumnya warna gambar yang akan dijadikan acuan gambar sablon berwarna hitam. Setiap satu warna yang akan di cetak dimedia sablon maka membutuhkan satu gambar. Pada Pengabdian Masayarakat kali ini membutuhkan dua gambar yang berbeda karena akan menghasilkan dua warna yaitu coklat dan kuning. Gambar bisa di cetak dengan menggunakan kertas kalkir atau kertas HVS yang diberi minyak sehingga trasnparant

5. Exposing adalah merekam atau mengalihkan gambar dari acuan sementara (berbentuk print out berwarna hitam diatas film positif atau kertas kalkir) ke permukaan screen yang telah diberi lapisan afdruk dan dikeringkan dengan bantuan cahaya. Bahan afdruk bersifat peka terhadap cahaya (photo sensitive), artinya jika bagian permukaan screen yang telah diberi afdruk terkena cahaya akan bereaksi (mengeras), sehingga bagian gambar yang akan kita buat harus berwarna hitam, agar dapat menghalangi cahaya mengenai sebagian permukaan screen yang telah diberi lapisan afdruk tersebut. Proses ini dilakukan \pm 5 menit dengan menggunakan cahaya buatan (lampu neon panjang) sebanyak 4 buah dengan jarak lampu dengan screen $\pm 15 \mathrm{~cm}$.

6. Developing. Screen yang telah diekspose selanjutnya dibasuh air untuk memunculkan gambar yang telah dialihkan, bisa juga dengan air bertekanan agar gambar mudah muncul, hasil dari proses ini dikatakan bagus apabila lapisan afdruk rontok pada bagian gambar (mesh bolong) dan tidak rontok pada bagian yang bukan gambar, setelah itu dikeringkan dengan bantuan pengering rambut atau bisa juga dengan cara dijemur dibawah sinar matahari.

7. Printing pada media kain. Setelah screen sudah memiliki pola gambar barulah masuk ke proses cetak, menggunakan jenis tinta rubber warna yang dapat diberi tambahan pigment warna dan memiliki sifat tebal ketika berada diatas permukaan media cetak berbahan tekstile. Prosesnya dengan meletakan tinta rubber warna yang telah dicampur pigment pada bagian dalam screen dan kemudian disapu 1 arah dengan menggunakan penyapu tinta atau rakel, sehingga tinta masuk atau tembus melalui sela sela lubang dan mengenai media cetak yaitu bahan tekstile, selanjutnya adalah mengeringkan tinta hasil sablon yang berada diatas permukaan media cetak dengan bantuan alat curing, heat press atau pengering rambut. Karena proses sablon manual memunyai keterbatasan jumlah tinta yang digunakan dalam 1 produk, maka design untuk produk hanya menggunakan 2 warna yaitu kuning dan coklat.
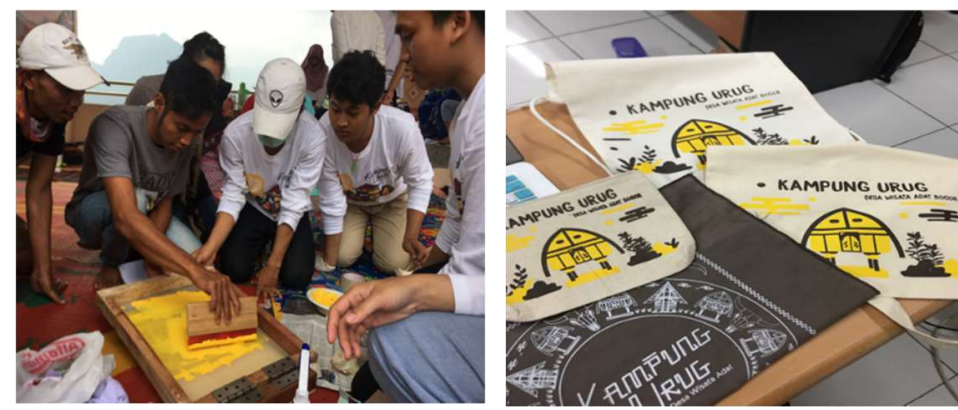

Gambar 1. Proses sablon manual pada media tekstil 
8. Untuk menghasilkan kualitaas yang baik diperlukan parameter sebagai berikut : material yang baik kualitasnya, tegnagan dan ketebalan screen, mesh, kekerasan, bentuk dan tekanan rakel emulsi, prosedur cetak, akurasi posisi dan pasta cetak yang bagus. Kalau semua itu dipenuhi maka akan menghasilkan produk yang bagus. (Sauer, 2004)

9. Cleaning (pembersihan screen). Langkah terakhir adalah proses pembersihan screen yang telah digunakan. jika ingin menggunakan screen dikemudian hari dengan model yang sama, yang perlu dibersihkan hanyalah tintanya saja bisa menggunakan air saja atau dengan bantuan sabun colek, namun jika ingin mengganti model yang lain maka perlu membersihkan lapisan afdruknya juga dengan menggunakan bahan remover.

\section{SIMPULAN}

Keterlibatan mitra seperti aparat pemerintahan setempat dan masyarakat desa Urug sebagai peserta pelatihan dan koordinasi lapangan pada saat Pengabdian Masayrakat berlangsung dapat meningktakan kemampuan warga untuk melakukan promosi terhadap wisata alam desa mereka. Aparat desa setempat beserta perwakilan masyarakat akan mengelola alat serta barang hasil pelatihan dan produk terutama saat ada kegiatan adat yang dibuka untuk umum di desa tersebut.

Bahan dan skill yang dibutuhkan untuk pelaksanan kegiatan ini sederhana dan terjangkau. Kebutuhan untuk kegiatan ini adalah alat produksi cetak sablon yang perawatan dan pemakaiannya mudah dilakukan secara mandiri sesuai dengan kebutuhan dan souvenir promosi pada media textile manual. Bahan yang diberikan yang nantinya akan di produksi kembali dengan mudah.

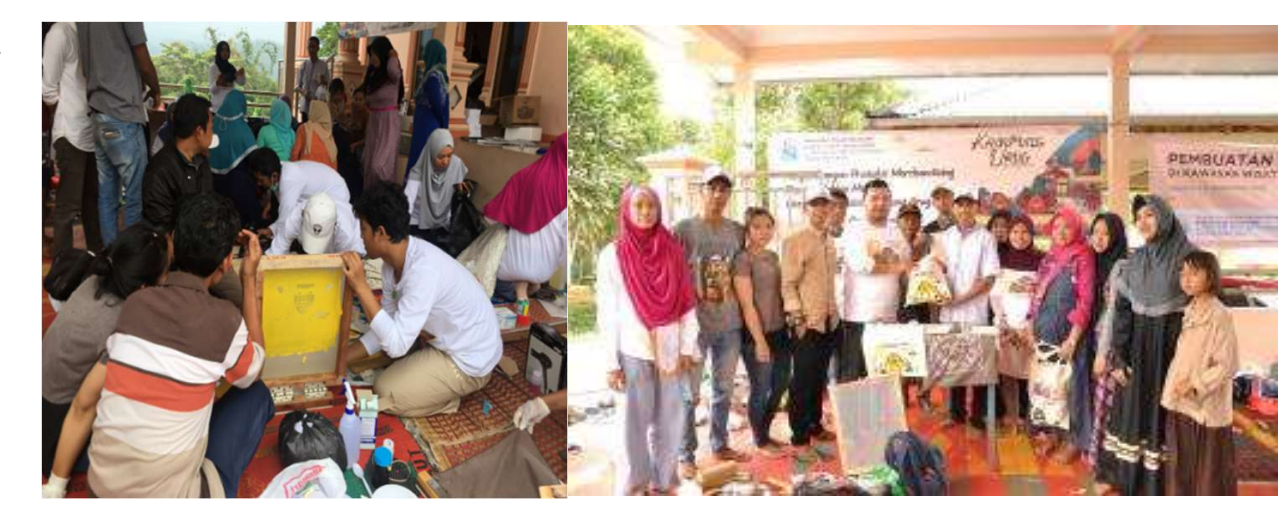

Gambar 2. Kegiatan pelatihan sablon manual pada media tekstil

\section{UCAPAN TERIMA KASIH}

Ucapan terima kasih diberikan kepada Politeknik Negeri Jakarta sebagai penyandang dana dan Kepala desa serta masyarakat Kampong Urug.

\section{DAFTAR PUSTAKA}

[1] Anon.,2018. jabarprov.go.id/index.php/potensi_daerah/ detail/237/1. [Online]

[2] Available at: http://jabarprov.go.id/ index.php/potensi_daerah/detail/237/1.
[3] Nugraha, A. R., 2017. MODELL KOMINIKASI PARIWISATA YANG BERBASIS KEARIFAN LOKAL. JURNAL THE MESSENGER, Volume 9.

[4] Putra, M. A. S., 2010. Evaluasi Pengembangan Ekowisata Desa Budaya Kertalangu di Desa Kesiman Kertalangu Kota Denpasar. Ecotrophic, 5(1), pp. 7379.

[5] Sauer, M., 2004. Screen Printing. Boston, MA: Springer. 